\title{
Harmonic Suppression of High-Power UPS in Power Network
}

\author{
Lv Changzhi, Geng Anran, and Pan Jiaxing
}

\begin{abstract}
Rectifier is a necessary part of high-power UPS. But due to its nonlinear characteristics, serious input current harmonic pollution will be produced to the power network. In this paper, by theoretical analysis, calculation and simulation, the necessity of input current harmonic suppression of high-power UPS rectifier is proved. Sseveral harmonic control methods of input current are proposed according to two aspects: adding harmonic compensation device and improving rectifier architecture. Finally, by on-line test and parameter comparison, the feasibility of the scheme is verified.
\end{abstract}

Index Terms-High-power UPS, rectifier, input current, harmonic.

\section{INTRODUCTION}

With the development of power electronics technology, as an important equipment to ensure the stability and continuity of power supply, high-power UPS is widely used in power system, and comprehensively protects the hardware equipment, operating procedure and data transmission path of the network. AC/DC rectifier is a necessary part [1]. But due to the nonlinear characteristics, necessary analysises to the harmonic problem is very important for the selection and extension of the UPS rectifying before putting into use[2].

Under ideal conditions, after applying AC input sine wave voltage to the UPS, the input current waveform is changed into a non sinusoidal wave. In the course of running, the large number of current harmonics will generate reactive power, bring serious danger to power generation equipment, power supply equipment and power using equipment, cause a serious pollution on the power network and pose a threat to the safe operation of low voltage power supply system and all kinds of electric equipments [3].

In order to ensure the range of input current harmonic content of high-power and find an effective way to reduce it[4], in the paper, theoretical analysis, calculation and simulation of the input current harmonics are carried out. Several control methods are proposed to reducing the input current harmonic pollution. Actual tests or simulations are conducted to prove its feasibility, providing a theoretical basis for the harmonic suppression of high-power UPS in

Manuscript received October 10, 2016; revised January 13, 2017. This work is partially supported by Natural Science Foundation of China (61305129), China Postdoctoral Science Foundation (2012M521361), Shandong Province Natural Science Foundation (ZR2013CQ017), Domestic Visiting Scholars Program of Outstanding Young Teachers in Colleges and Universities in Shandong.

Lv Changzhi, Geng Anran and Pan Jiaxing are with Colege of Electrical Engineering and Automation, Shandong University of Science and Technology, Shandong, Qingdao 266590 China (e-mail: lvchangzhi@126.com,18765275951@163.com, hljpjx@126.com.) practical application.

\section{HARMONIC ANALYSIS}

\section{A. Theoretical Analyseie}

6 pulse rectifier is a common rectifying device of high-power UPS, which has a full bridge rectifier consisting of six thyristo and is controlled by six thyristor respectively. Its schematic diagram is shown in Fig. 1.

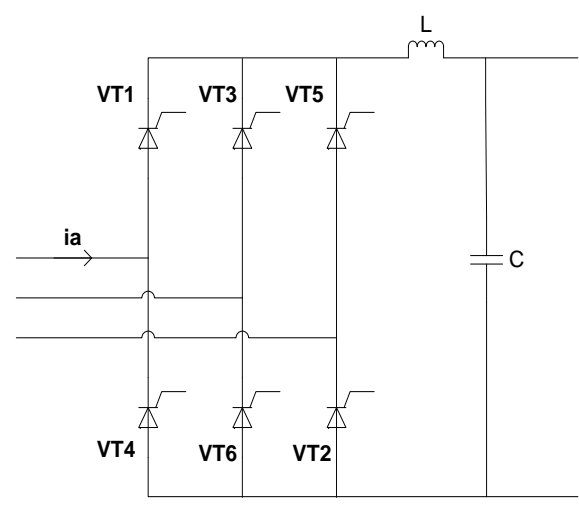

Fig. 1. 6 pulse rectifier.

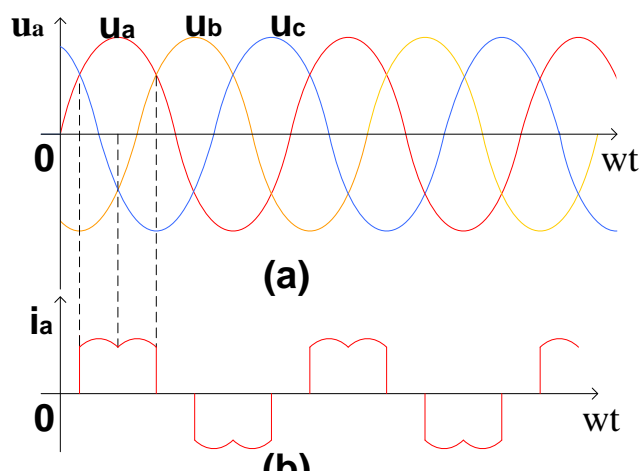

(b)

Fig. 2. 6 pulse rectifier waveform (a) AC voltage (b) A phase current.

Ignore phase change process and current pulse and the effect of the harmonic of power supply, assumed that the AC voltage is pure sine wave, the AC side reactance is zero and trigger delay angle $\alpha=0.6$ pulse rectifier (a) AC side voltage waveform (b) A phase current waveform is shown in Fig. 2. While the input sine wave voltage flows through the rectifier bridge, the input current is not a sine wave but a saddle shaped wave, its positive or negative half cycle of each wide is $120^{\circ}$ and the front difference is $180^{\circ}$ [5].

\section{B. Harmonic Calculation and Total Harmonic Distortion}

Taking A phase current as an example, assuming that the trigger delay angle $\alpha=0$ and DC side inductance is infinite, 
the average value of the DC side output current $I_{d}$ is known.

A phase RMS current $I_{a}$ is as follows:

$$
I_{a}=\sqrt{\frac{1}{2 \pi} \int_{0}^{2 \pi} i_{a}^{2}(\omega t) d_{\omega t}}=\sqrt{\frac{1}{\pi} \int_{0}^{2 \pi / 3} I_{d}{ }^{2} d_{\omega t}}=\sqrt{\frac{2}{3}} I_{d}
$$

In one cycle, the instantaneous value of AC side current is:

$$
\left\{\begin{array}{cc}
i_{a}(\omega t)=0 & \left(0 \leq \omega t<\frac{\pi}{6}\right) \\
i_{a}(\omega t)=I_{d} & \left(\frac{\pi}{6} \leq \omega t<\frac{5 \pi}{6}\right) \\
i_{a}(\omega t)=0 & \left(\frac{5 \pi}{6} \leq \omega t<\frac{7 \pi}{6}\right) \\
i_{a}(\omega t)=-I_{d} & \left(\frac{7 \pi}{6} \leq \omega t<\frac{11 \pi}{6}\right) \\
i_{a}(\omega t)=0 & \left(\frac{11 \pi}{6} \leq \omega t<2 \pi\right)
\end{array}\right.
$$

The non sinusoidal input current $i_{a}(\omega t)$ with a period of $T=2 \pi / \omega$ meets the Dirichlet condition and can be decomposed into Fourier function:

$$
\begin{aligned}
& i_{a}(\omega t)=I_{0}+\sum_{n=1}^{\infty}\left(I_{a n} \cos n \omega t+I_{b n} \sin n \omega t\right) \\
& =I_{0}+\sum_{n=1}^{\infty} I_{m n} \sin \left(n \omega t+\varphi_{n}\right)
\end{aligned}
$$

Among that:

$$
I_{0}=\frac{1}{2 \pi} \int_{0}^{2 \pi} i_{a}(\omega t) d \omega t=0
$$$$
I_{a n}=\frac{1}{\pi} \int_{0}^{2 \pi} i_{a}(\omega t) \cos n \omega t d \omega t=0
$$$$
I_{b n}=\frac{1}{\pi} \int_{0}^{2 \pi} i_{a}(\omega t) \sin n \omega t d \omega t=\left\{\begin{array}{cc}
\frac{2 \sqrt{3}}{\pi} I_{d} & n=1 \\
(-1) \frac{k}{\frac{2 \sqrt{3}}{\pi}} I_{d} & n=6 k \pm 1 \\
0 & \text { Other }
\end{array}\right.
$$$$
I_{m n}=\sqrt{I_{a n}^{2}+I_{b n}^{2}}=\left\{\begin{array}{cl}
\frac{2 \sqrt{3}}{\pi} I_{d} & n=1 \\
(-1) \frac{k \sqrt{3}}{\pi} I_{d} & n=6 k \pm 1 \\
0 & \text { Other }
\end{array}\right.
$$

$\varphi_{n}=\arctan \left(\frac{I_{a n}}{I_{b n}}\right)=0$

According to (3) and (4), the Fourier expression for the input current $i_{a}(\omega t)$ can be obtained that: $i_{a}(\omega t)=\frac{2 \sqrt{3}}{\pi} I_{d} \sin \omega t+\frac{2 \sqrt{3}}{\pi} I_{d} \sum_{\substack{n=6 k \pm 1 \\ k=1,2, \cdots}}(-1) \frac{k}{n} \sin \omega t$

So the RMS current of the fundamental and each harmonic wave are:

$$
\left\{\begin{array}{c}
I_{1}=\sqrt{2} I_{m 1}=\frac{\sqrt{6}}{\pi} I_{d} \\
I_{n}=\sqrt{2} I_{m n}=\frac{\sqrt{6}}{n \pi} I_{d} \quad n=6 k \pm 1, k=1,2,3 \cdots
\end{array}\right.
$$

The $n$ times input harmonic current $H R I_{n}$ is:

$$
H R I_{n}=\frac{I_{n}}{I_{1}} \times 100 \%=\frac{1}{n}
$$

The total harmonic distortion of input current $T H D_{i}$ is:

$T H D_{i}=\frac{\sqrt{I^{2}-I_{1}^{2}}}{I_{1}} \times 100 \%=\frac{\sqrt{\frac{2}{3} I_{d}^{2}-\frac{6}{\pi^{2}} I_{d}^{2}}}{\frac{\sqrt{6}}{\pi} I_{d}}=31.08 \%$

\section{Simulation}

To prove the correctness of the calculation above, the MATLAB simulation of 6 pulse rectifier is carried out.

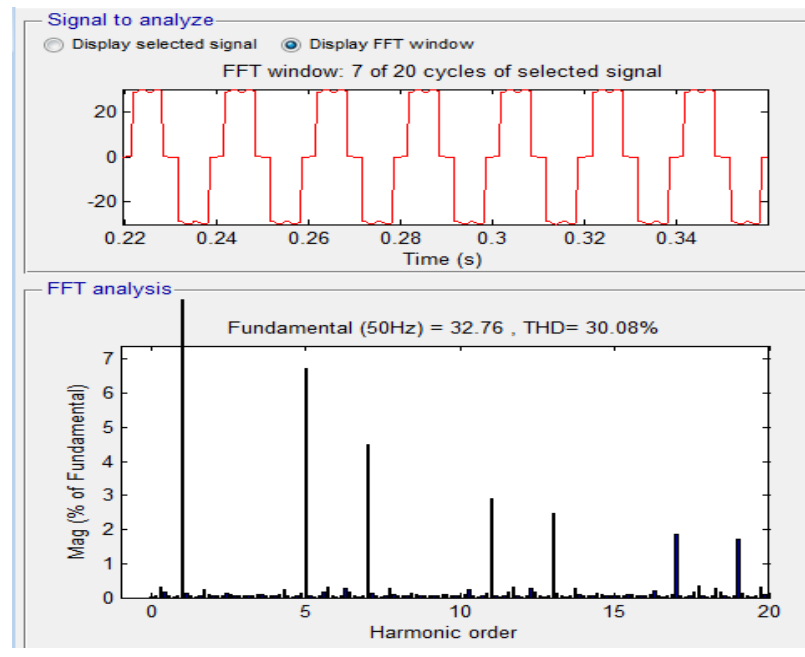

Fig. 3. A phase input current waveform, harmonic spectrum.

In the simulation, the AC voltage of the circuit is ideal, $220 \mathrm{~V}, 50 \mathrm{~Hz}$, with a resistance and inductance load. A phase input current waveform and harmonic spectrum are shown in Fig. 3. The input current waveform is distorted, each harmonic rate decreases with the increase of frequency, and 5th and 7th harmonic amplitude is relatively higher which are about $1 / 5$ and $1 / 7$ of the fundamental respectively[6]. The input current $T H D_{i}$ is $30.08 \%$, similar to the theoretical calculation, indicating that the distortion is serious and will cause a bad pollution for the power system [7]. 


\section{DifFERENT Harmonic CONTROL Methods AnAlysis}

\section{A. Increase Harmonic Compensation Device}

By adding passive filter or active filter, once or more harmonics produced by a UPS rectifier can be compensated. The passive filter schematic diagram is shown in Fig. 4. It can be seen that the filter inductor $\left(\mathrm{L}_{\mathrm{A} 1}, \mathrm{~L}_{\mathrm{B} 1}, \mathrm{~L}_{\mathrm{C} 1}\right)$ and filter capacitor $\left(\mathrm{C}_{1}, \mathrm{C}_{2}, \mathrm{C}_{3}\right)$ present a low impedance characteristic to $5^{\text {th }}$ and $7^{\text {th }}$ harmonics and can effectively filter the suppression; The input inductoris $\left(\mathrm{L}_{\mathrm{A}}, \mathrm{L}_{\mathrm{B}}, \mathrm{L}_{\mathrm{C}}\right)$ is used as a input current waveform correction which can improve the effect of the resonant filter circuit[8]. The active filter schematic diagram is shown in Fig. 5. By the instruction current detection circuit and compensation current generation circuit, it can detect the power side harmonic component and generate a additional signal opposite [9]. And can suppress harmonics dynamically. The active filter can compensate harmonics in different size and frequency [10].

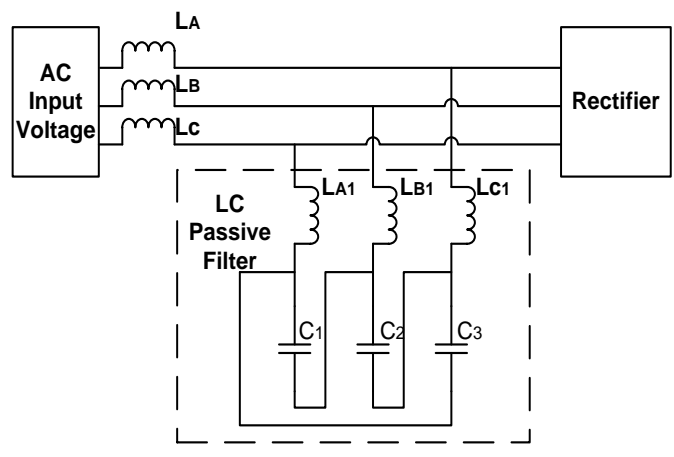

Fig. 4. Passive Filter.

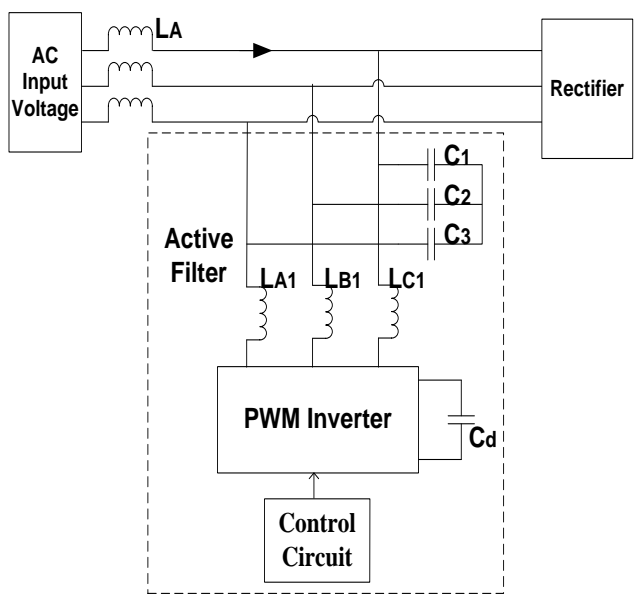

Fig. 5. Active filter.

\section{B. Improve UPS Rectifier's Structure}

12 pulse and IGBT rectifier are two feasible methods.

The diagram of 12 pulse rectifier is shown in Fig. 6. The circuit is composed of two 6 pulse rectifier, connected in parallel and with the same polarity. By different connection of the transformer, the phase difference between the two rectifier bridges is $30^{\circ}[11]$. Taking A phase current as an example, assuming that the AC input voltage is pure sine wave and the trigger delay angle $\alpha=0$, the Fourier series equations of this two rectifier bridge are:

$$
\left\{\begin{array}{c}
i_{a 1}(\omega t)=\frac{2 \sqrt{3}}{\pi} I_{d} \sin \omega t+\frac{2 \sqrt{3}}{\pi} I_{d} \sum_{\substack{n-6 k \pm 1 \\
k=1,2 \cdots}}(-1)^{k} \frac{1}{n} \sin \omega t \\
i_{a 2}(\omega t)=\frac{2 \sqrt{3}}{\pi} I_{d} \sin \omega t+\frac{2 \sqrt{3}}{\pi} I_{d} \sum_{\substack{n-6 k \pm 1 \\
k=1,2 \cdots}} \frac{1}{n} \sin \omega t
\end{array}\right.
$$

So the total input current $i_{a}(\omega t)$ Fourier series equation is:

$$
i_{a}(\omega t)=\frac{4 \sqrt{3}}{\pi} I_{d} \sin \omega t+\frac{4 \sqrt{3}}{\pi} I_{d} \sum_{\substack{n=12 k \pm 1 \\ k=1,2 \cdots}} \frac{1}{n} \sin \omega t(10)
$$

From the equations, the input current harmonics of 12 pulse rectifier is $n=12 k \pm 1, k=1,2 \cdots$, the maximum harmonic component appears in the $11^{\text {th }}$, accounting for $1 / 11$ of the fundamental, without $5^{\text {th }}$ or $7^{\text {th }}$ harmonic[12]. Compared with 6 pulse rectifier, the harmonic content is reduced and the total harmonic distortion rate will decrease, so it can reduce the input current harmonic pollution of rectification part effectively.

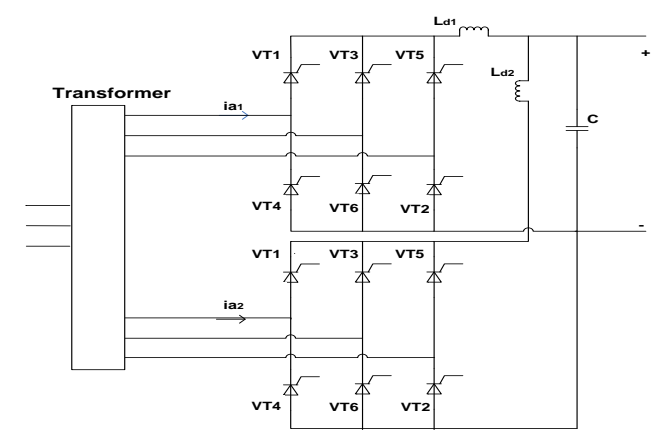

Fig. 6. 12 Pulse thyristor rectifier.

IGBT rectifier uses full control device instead of thyristor, uses PWM control mode instead of phase controlled rectifier[13] and its schematic diagram is shown in Fig. 7. By modulation, IGBT rectifier can make the input current track the input voltage waveform, absorb sinusoidal current in the same phase with voltage and will only produce a very small pulse because of the high ordered harmonic associated with triangular carriers[14]. So the input current waveform is close to sine wave, the power factor is close to 1 and each harmonic content is small. It can be use to reduce the harmonic content [15].

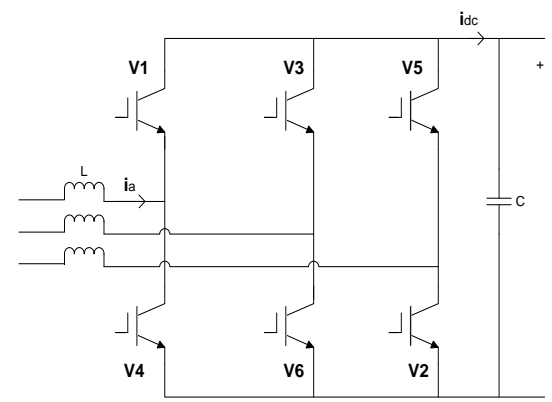

Fig. 7. IGBT rectifier. 


\section{SiMUlATION AND EXPERIMENT OF DiFFERENT TREATMENT METHODS}

\section{A. 6 Pulse Rectifier}

Take a certain model $40 \mathrm{kVA}, 380 \mathrm{~V}, 50 \mathrm{~Hz}$ UPS using 6 pulse rectifier as an example and do an oscilloscope test. With a linear full load, a phase voltage and current waveforms are shown in Fig. 8. It can be seen that after putting into the power network, the AC current waveform is not linear with the voltage waveform, the phase difference between the voltage and the fundamental current is $30^{\circ}$, and the current waveform is a distorted saddle shaped wave. The input power factor and total current harmonic distortion rate test of 6 pulse rectifier is shown in Table 1 and it can be seen that the PF and $T H D_{i}$ data are about 0.81 and 25\%. Power factor can affect the load capacity of UPS, and harmonic pollution can affect the power quality of power system. Effective managements need to be put to meet the two requirements.

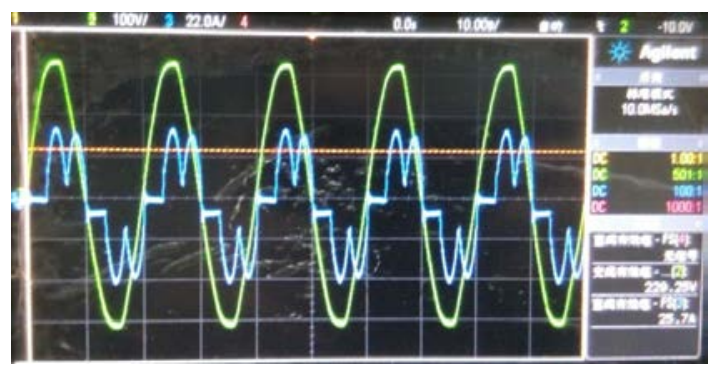

Fig. 8. A phase voltage and current waveforms.

TABLE I: THE INPUT PF AND THD $i$ TEST OF A CERTAIN TYPE UPS USING

\begin{tabular}{l|l|l|l}
\multicolumn{5}{c}{$6 \mathrm{P}$} \\
\hline \hline $\begin{array}{l}\text { THDU OF PHASE A OF } \\
\text { MAIN INPUT: }\end{array}$ & $0.65 \%$ & $\begin{array}{l}\text { TOTAL CURRENT } \\
\text { TEST VALUE (A): }\end{array}$ & $\begin{array}{l}116.0 \\
2\end{array}$ \\
\hline $\begin{array}{l}\text { TOTAL CURRENT } \\
\text { LCD DISPLAY } \\
\text { VALUE (A): }\end{array}$ & 116.70 & $\begin{array}{l}\text { ACCURACY OF } \\
\text { INPUT CURRENT } \\
\text { DISPLAY: }\end{array}$ & $0.59 \%$ \\
\hline \multirow{2}{*}{ N/A } & EACH ORDER OF POWER FACTOR \\
\cline { 2 - 4 } $\begin{array}{l}\text { INPUT PF (100\% } \\
\text { LOAD) }\end{array}$ & 0.812 & B & C \\
\hline \multirow{2}{*}{$\begin{array}{l}\text { N/A } \\
\text { EACH ORDER OF HARMONICS }\end{array}$} & 0.801 & 0.811 \\
\hline $\begin{array}{l}\text { INPUT THD }(100 \% \\
\text { LOAD })\end{array}$ & PERCENTAGE (\%) & B & C \\
\cline { 2 - 4 } & A 25.080 & 24.940 & 25.620 \\
\hline
\end{tabular}

TABLE II: THE INPUT PF AND THD ${ }_{i}$ TEST OF A CERTAIN TyPE 6P UPS

\begin{tabular}{l|l|l|l|l}
\hline \multicolumn{5}{|c}{ WITH 5TH FILTER } \\
$\begin{array}{l}\text { THDU OF PHASE A OF } \\
\text { MAIN INPUT: }\end{array}$ & $0.46 \%$ & $\begin{array}{l}\text { TOTAL CURRENT TEST } \\
\text { VALUE (A): }\end{array}$ & 98.46 \\
\hline $\begin{array}{l}\text { TOTAL CURRENT LCD } \\
\text { DISPLAY VALUE (A): }\end{array}$ & 98.60 & $\begin{array}{l}\text { ACCURACY OF INPUT } \\
\text { CURRENT DISPLAY: }\end{array}$ & $0.14 \%$ \\
\hline \multirow{2}{*}{ N/A } & EACH ORDER OF POWER FACTOR \\
\cline { 2 - 4 } & A & B & C \\
\hline $\begin{array}{l}\text { INPUT PF (100\% } \\
\text { LOAD) }\end{array}$ & 0.935 & 0.929 & 0.935 \\
\hline \multirow{2}{*}{$\begin{array}{l}\text { N/A } \\
\text { EACH ORDER OF HARMONICS PERCENTAGE } \\
(\%)\end{array}$} & A & B & C \\
\cline { 2 - 4 } $\begin{array}{l}\text { INPUT THDI (100\% } \\
\text { LOAD) }\end{array}$ & 8.570 & 7.940 \\
\hline \hline
\end{tabular}

\section{B. Increase Harmonic Compensation Device}

The maximum input current harmonic component of 6 pulse rectifier appears on the 5th, so 5th harmonic filters can be added to filter out the current harmonic component of 5th and its adjacent spectrum neighby. As shown in table II, compared with table I, the input PF can be greater than 0.90 and the $T H D_{i}$ can be reduced under $10 \%$ after adding 5th filter. So, in ths way, it can improve the power factor and partly reduce the harm current harmonic to the power network. Although the input current harmonics is still large, it is of high reliability, good cost performance and a great feasibility in using passive components.

\section{Improve the Structure of UPS Rectifier}

Assuming that $220 \mathrm{~V}, 50 \mathrm{~Hz}$ AC input voltage is a pure sine wave, AC side reactance is zero and DC side load is inductive, after 12 pulse rectifier simulation, A phase input voltage and current waveform, harmonic spectrum diagram is shown in Fig. 9. It can be seen the input current waveform is distorted and not in the same phase as input voltage. But compared with 6 pulse rectifier, the maximum harmonic component appears in the 11th and the total harmonic distortion is less than 5\%. Although the device and control circuits are complex and the reliability needs to be proved, the total harmonic distortion rate shows that 12 pulse rectifier can be used in UPS harmonic control. In actual operation, the 11th harmonic is still large, the 11th harmonic filter can be used to reduce it.

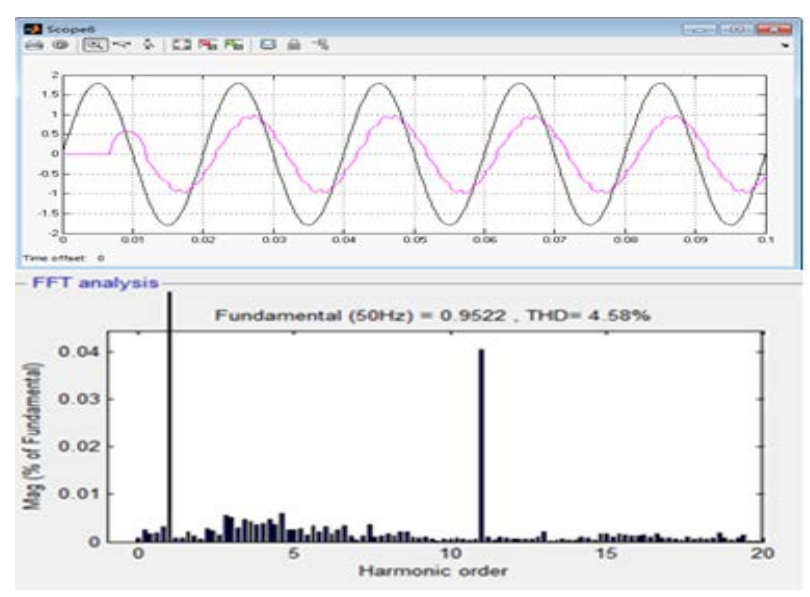

Fig. 9. A phase input voltage, current waveform and harmonic spectrum of 12 pulse rectifier.

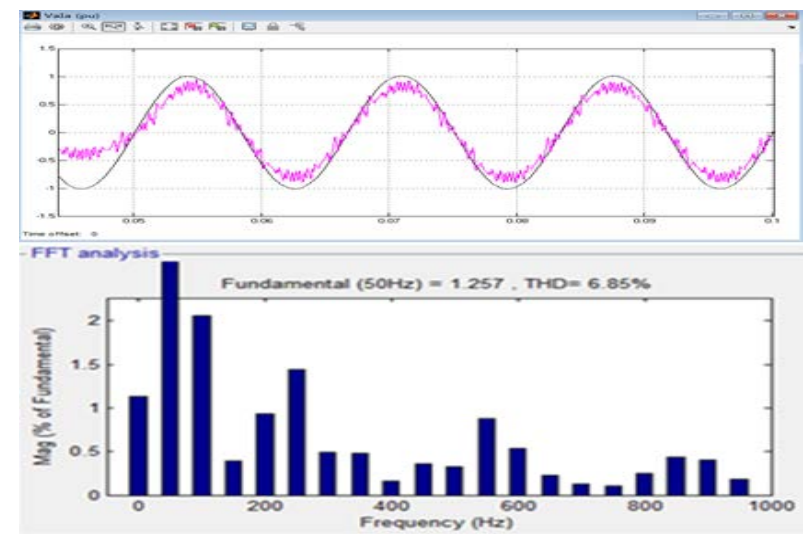

Fig. 10. A phase voltage current waveform and current harmonic spectrum of IGBT rectifier. 
After the simulation of the IGBT rectifier, A phase voltage and current waveform and current harmonic spectrum are shown in Fig. 10. The input current is close to a sine wave and basicly basically in the same phase with the input voltage and the power factor is approximately 1 . Compared with 6 pulse rectifier, the harmonic content and total harmonic distortion rate are lower. Using IGBT rectifier in high-power UPS can effectively restrain the harmonics and improve power quality. But at the same time, the control system is more complex, and need to solve the pollution of high order current harmonics to the power network.

\section{CONCLUSION}

In this paper, we analyzed theoretically and calculated the harmonic problem caused by high-power UPS after inputing into power network, discussed some relevant solutions and get some conclusions by comparing the data of simulation and actual test. Firstly, compared with 6 pulse rectifier, increasing harmonic compensation device and improving the structure of UPS rectifier can effectively reduce the harmonic content, but the compensation way of filtering compensators is pollute first, then control. Secondly, the control method of 12 pulse rectifier is to reduce the times of harmonics fundamentally. Thirdly, IGBT uses a completely different control strategy from traditional ones and has a greater advantage in reducing harmonic content and improving the power factor. To make a final textual research of each method, long-term operation and monitoring in working conditions are needed.

\section{REFERENCES}

[1] X. X. Liao, Z. H. Zhuang, W. X. Ke, and Z. S. Ding, "Study on harmonic reductions of IDC rooms," Electrical Technology of Intelligent Building, vol. 5, pp. 69-71, 2011.

[2] J. S. Yuan and Y. Bi, "Process and temperature robust voltage multiplier design for rf energy harvesting," Microelectronics Reliability, vol. 55, pp. 107-113, January 1, 2015.

[3] P. Zhang, D. P. Zhou, and S. Na, "An introduction to the harmonic pollution of the UPS supply water chilling unit," Electrical Automation, vol. 34, pp. 65-73, 2012

[4] J. F. Cao, "Harmonic analysis of three phase bridge rectifier circuit," Silicon Valley, vol. 16, pp. 1671-7597, 2014.

[5] G. G. Huang, "UPS harmonic control," The World of Power Supply, vol. 09, pp. 42-49, 2009.

[6] X. P. Guo and H. X. Pang, "Application of eliminating harmonic technology in communication company," Chinese Journal of Power Sources, vol. 37, pp. 461-464, 2013.

[7] S. Parthasarathy, P. Loganthurai, S.Selvakumaran, and V. Rajasekaran, "Harmonic mitigation in UPS system using PLL," in Proc. 2011 2nd International Conf. on Advances in Energy Engineering, ICAEE 2011, pp. 873-879, vol. 14, 2012.

[8] X. Ma, H. J. Liu, Z. H. Zhang, X. Cui, and X. Y. Guo, "Application of pasive strategy in single-phase active power filter for harmonic and inter-harmonics unity compensation," Power System Technology, vol. 39, pp. 1419-1424, May 2015.

[9] M. T. Chau, "The research of hybrid active power filter," Ph.D. dissertation, Dept. Elect. Eng., Hunan Univ., Changsha, China, 2012.

[10] J. S. Yuan, Y. Xu, S. D. Yen, Y. Bi, and G. W. Hwang, "Hot carrier injection stress effect on a $65 \mathrm{~nm}$ LNA at $70 \mathrm{GHz}$," IEEE Transactions on Device and Materials Reliability, vol. 14, pp. 931-934, 2014.
[11] X. W. Xie, M. Wang, and F. H. Zhang, "12-pulse auto-transformer rectifier unit with current harmonic injection," Power Electronics, vol. 37, pp. 461-464, 2011.

[12] F. G. Memg, W. Yangi, and S. Y. Yang, "Active harmonic suppression of paralleled 12-pulse rectifier at DC side," Science China Press and Springer-Verlag Berlin Heidelberg, vol. 37, pp. 461-464, 2011.

[13] T. Noguchi and K. Sano, "Specific harmonic power suppression of direct power-controlled current-Source PWM rectifier," IEEE Conference Publications, vol. 37, pp. 461-464, 2007.

[14] X. Yin, “The Research on Three-phase PWM Rectifier for UPS,” Ph.D. dissertation, Dept. Elect. Eng., Huazhong Univ. of Science \& Technology, Wuhan, China, vol. 2012.

[15] Y. J. Wang, W. C. Wang, C. Wang, and X. J. Wu, "Coupling analysis on current control at low switching frequency for the three-phase PWM converter based on RGA and a novel output feedback decoupling method," IEEE Trans. on Industrial Electronics, vol. 63, pp. 6684-6694, 2016.

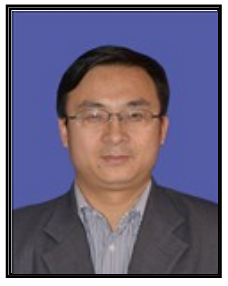

Lv Changzhi was born in May 1971, a doctor of surveying instruments and systems in College of Geomatics, Shandong University of Science and Technology, Qingdao, Shandong, China, in Sept. 2011; a master of measurement technology and instruments in College of Electrical and Electronic Engineering, Shandong University of Science and Technology from Sept. 1997 to June 2002.; a bachelor of industrial automation in Electrical Institution, Shandong Institute of Mining and Tecnology, Taian, Shandong, China from Sept. 1990 to June 1994.

From Jan. 2013 to Dec. 2016, he undertakes two National Natural Science Youth Fund Project; From Aug. 2008 to Aug. 2011, undertook International cooperation project of Ministry of science and technology. Published two SCI and 12 EI papers. Publishing book: Digital Electronic Technology (Beijing, China: Peking University Press, 2006). Research direction: electric power system and automation, detection technique and automatic device and automatic control technology.

Assoc. Prof. Lv, supervisor for postgraduates in Shandong University of Science and Technology. Awards: in April 2015, he won the guidance teacher award of Shandong University of Science and Technology; in Oct. 2015, he won the outstanding instructor award of the fourth Robot Contest of Shandong provincial universities; in Aug. 2016, he won the first prize of Shandong Electronic Design Competition, Shangdong Provincial Department.

Geng Anran was born in April 1991. She is a master of electric power system and automation in College of Electrical Engineering and Automation, Shandong University of Science and Technology, Qingdao, Shandong, China in Sept. 2015

She studies well, is recommended to become a graduate student, helps teacher do a lot of researches, majoring in automation of electric power system.

Award: in Aug. 2016, he won the first prize of National college student intelligent Internet Innovation Contest, Chinese Electronics Society.

Pan Jiaxing was born in April 1992. He is a master of electric power system and automation, in College of Electrical Engineering and Automation, Shandong University of Science and Technology, Qingdao, Shandong, China in Sept. 2015.

He studies well. His published papers included: The Micro Control Low Voltage Reactive Power Compensation Controller (Guangzhu,Guangdong: Electronics Quality in Aug. 2016); Design of vehicle mounted battery charge and discharge converter(accepted by Automobile technology in Aug. 2016).

Award: in Aug. 2013, he won the third-prize of the Eighth National University "Freescale" Shandong division Cup Smart Car Race; in 2015, he won the Second-prize of Shandong Robot Competition. 